\title{
RESPOSTAS FISIOLÓGICAS EM QUARTO-DE-MILHA APÓS PROVA DE TAMBOR
}

\author{
Physiological answers in quarter horses after barrel racing
}

\author{
Elder Clayton Capelleto $^{[a]}$, Ana Laura Angeli ${ }^{[b]}$, Henriete Graff ${ }^{[c]}$ \\ [a] Aluno de graduação do Curso de Medicina Veterinária da Universidade Tuiuti do Paraná (UTP), Curitiba, PR - Brasil, e-mail: \\ ecapelletto@gmail.com \\ ${ }^{[b]}$ Médica Veterinária, professora doutora de Fisiologia e Equideocultura do Curso de Medicina Veterinária da Universidade Tuiuti \\ do Paraná (UTP), Curitiba, PR - Brasil, e-mail: ana.angeli@utp.br \\ ${ }^{[c]}$ Médica Veterinária, Mestre em Ciências Veterinárias, Equivet, Curitiba, PR - Brasil, e-mail: equivet.vet@hotmail.com
}

\begin{abstract}
Resumo
O objetivo do presente estudo foi o de correlacionar a frequência cardíaca máxima e os valores do eritrograma e do leucograma pós-competição, com o tempo obtido em provas de tambor em cavalos da raça quarto-de-milha. Seis equinos atletas da raça quarto-de-milha foram utilizados três machos e três fêmeas. A avaliação de desempenho atlético foi realizada durante a competição de tambor, onde foram avaliados o eritrograma e o leucograma a partir de sangue colhido da veia jugular, imediatamente após o término da prova, bem como a frequência cardíaca (FC) que foi avaliada durante a prova, por meio de frequencímetro adaptado a cada indivíduo. O tempo obtido pelo cronômetro oficial da prova, em cada passada nos tambores, foi anotado em ficha apropriada. Os indivíduos testados apresentaram valores de média e desvio-padrão para hematócrito ígual a $55 \pm 1,4 \%$, eritrócitos totais igual a 9,52 $\pm 0,6$ milhão/ $\mu 1$, leucócitos $11.891 \pm 2.046 \mathrm{~mm}^{3}$, fibrinogênio $0,26 \pm 0,08 \mathrm{~g} / \mathrm{dl}, \mathrm{FCmax} .208 \pm 4,5 \mathrm{bpm}$ e tempo de prova de 19,33 \pm 0,6 segundos. Os resultados indicam influência positiva dos altos valores da contagem total de eritrócitos e da frequência cardíaca sobre o menor tempo de prova obtido por cavalos da raça quarto-de-milha.
\end{abstract}

Palavras-chave: Exercício. Hemograma. Equinos. Frequência cardíaca.

\begin{abstract}
The aim of this research was to correlate the heart rate peak and the haematological values to the time obtained by quarter horses during barrel racing. Six horses - three males and three females - were submitted to the test. Performance evaluation during competition was hematological analysis exams after the exercise to the heart rate evaluated every five seconds using appropriate device. The time obtained during the race was recorded as well. The animals
\end{abstract}


had mean and standard deviation values of haematocrit of $55 \pm 1.4 \%$, red blood cells count of $9.52 \pm 0.6$ million/ $\mu l$, leucocytes count of $11.891 \pm 2.046 \mathrm{~mm}^{3}$, fibrinogen of $0.26 \pm 0.08$ $\mathrm{g} / \mathrm{dl}$, maximum heart rate peak of $208 \pm 4.5 \mathrm{bpm}$ and racing time of $19.2 \pm 0.7$ seconds. Results indicate a positive influence of the high values of red blood cells count and heart rate on the shorter time during competition obtained by quarter horses.

Keywords: Exercise. Haematological analysis. Horses. Heart rate.

\section{INTRODUÇÃO}

O cavalo quarto-de-milha e seus mestiços são muito utilizados no Brasil para a prática de vários esportes equestres como: corridas em curtas distâncias, tambor, baliza, vaquejada, polo e provas de rodeio em geral.

O desempenho atlético requer a interação complexa de mecanismos que envolvem os sistemas musculoesquelético, nervoso, respiratório e cardiovascular (COUROUCÉ, 1999; NIELSEN et al., 2006). O condicionamento físico e a capacidade de desempenho são importantes nos diversos esportes equestres, embora haja dificuldade em avaliá-los de forma objetiva e confiável (OLDRUITENBORGH-OOSTERBAAN; CLAYTON, 1999).

As avaliações de desempenho podem ser realizadas em laboratório equipado com esteira de alta velocidade ou a campo pelo controle da velocidade por meio de cronômetros (ANGELI; LUNA, 2008; MARLIN; NANKERVIS, 2002) e envolvem a avaliação das relações entre a velocidade do animal e a frequência cardíaca, a velocidade e o lactato sanguíneo, eritrograma e leucograma pré e pós-exercício e consumo de oxigênio (EVANS, 2007).

Os protocolos de avaliação a campo incluem aumentos graduais da velocidade com amostras de sangue colhidas em cada intervalo, picos de exercícios submáximos ou pico único de exercício máximo. A mensuração da frequência cardíaca e de variáveis hematológicas e bioquímicas é comumente realizada nos testes a campo (HINCHCLIFF et al., 2007).

A frequência cardíaca $(\mathrm{FC})$ é um dos testes mais simples de se realizar durante o exercício, fornecendo índice indireto de capacidade e função cardiovasculares. Em geral, há aumento linear na FC que acompanha o aumento da velocidade do exercício até o ponto em que a $\mathrm{FC}$ máxima é obtida - $\mathrm{FC}_{\max }$ (MARLIN; NANKERVIS, 2002).

A $\mathrm{FC}_{\max }$ é uma determinação individual e altamente repetitiva em equinos a cada nova avaliação de performance, porém, quando avaliada isoladamente, não é parâmetro importante de condicionamento atlético por não ser afetada pelo treinamento (EVANS, 2007).

A velocidade em que o cavalo atinge a $\mathrm{FC}_{\max }\left(\mathrm{V}_{\mathrm{FC} \max }\right)$ é o melhor indicador da capacidade cardiovascular (COUROUCÉ, 1999). A V $\mathrm{FC}_{\max }$ pode variar de acordo com o condicionamento do atleta. Quanto mais alta esta velocidade, melhor o condicionamento (NOSTELL et al., 2006).

De acordo com Conceição et al. (2001), as determinações de hemograma e dos exames bioquímicos foram fundamentais para o início da compreensão das modificações fisiológicas que ocorrem durante o exercício em cavalos atletas. Entretanto, os valores hematológicos antes e imediatamente após a corrida parecem não estarem relacionados ao desempenho atlético de equinos (REVINGTON, 1983).

O objetivo da presente pesquisa foi correlacionar o pico da frequência cardíaca e os valores do eritrograma e do leucograma pós-competição, ao tempo obtido em provas de tambor em cavalos da raça quarto-de-milha. 


\section{MATERIAL E MÉTODOS}

Foram utilizados seis equinos atletas da raça quarto-de-milha, sendo três machos e três fêmeas. Os animais escolhidos estavam de acordo com os seguintes requisitos: higidez ao exame físico, hemograma prévio normal e participação em competições profissionais. Os animais foram submetidos a exame clínico rigoroso antes de sua inclusão na pesquisa, realizado pelo veterinário responsável.

A avaliação de desempenho atlético foi realizada durante a prova de tambor, onde foram avaliados o eritrograma e o leucograma a partir de sangue colhido da veia jugular, imediatamente após o término da prova e a frequência cardíaca (FC) que foi avaliada durante a prova, por meio de frequêncímetro ${ }^{1}$ adaptado a cada indivíduo. A FC foi registrada a cada 5 segundos, sendo posteriormente avaliada em gráfico em programa de computador ${ }^{2}$. O tempo obtido pelo cronômetro oficial da prova, em cada passada nos tambores, foi anotado em ficha apropriada.

Os dados foram analisados descritiva e estatisticamente pelo método de Mann Whitney para a comparação dos vários dados entre os seis animais. Valores de $\mathrm{p}<0,05$ foram considerados significativos.

\section{RESULTADOS}

Os indivíduos testados apresentaram valores de média e desvio-padrão para hematócrito igual a $55 \pm 1,4 \%$, eritrócitos totais igual a 9,52 \pm 0,6 milhão/ml, leucócitos $11.891 \pm 2.046 \mathrm{~mm}^{3}$, fibrinogênio $0,26 \pm 0,08 \mathrm{~g} / \mathrm{dl}$, pico de FC $208 \pm$ 4,5 bpm (Figura 1) e tempo de prova de 19,33 \pm 0,6 segundos. Os dados estão apresentados na Tabela 1.

TABELA 1 - Hematócrito, contagem total de eritrócitos e leucócitos, fibrinogênio, pico de freqüência cardíaca (FC) e tempo em segundos da prova de prova de tambor em cavalos quartos de milha

\begin{tabular}{lllllll}
\hline Animal & A1 & A2 & A3 & A4 & A5 & A6 \\
\hline Sexo & Fêmea & Macho & Macho & Fêmea & Macho & Fêmea \\
Hematócrito $(\%)$ & 56 & 55 & 55 & 54 & 57 & 53 \\
Eritrócitos (milhão/ $\mu \mathrm{l})$ & 10,09 & 9,14 & 8,82 & 9,35 & 10,50 & 9,23 \\
Leucócitos $\left(\mathrm{mm}^{3}\right)$ & 10.350 & 15.500 & 9.750 & 12.500 & 11.150 & 12.100 \\
Fibrinogênio $(\mathrm{g} / \mathrm{dl})$ & 0,2 & 0,4 & 0,3 & 0,2 & 0,2 & 0,3 \\
Pico de FC & 208 & 207 & 203 & 214 & 212 & 205 \\
Tempo da prova $(\mathrm{s})$ & 18 "792 & 19 "139 & 20 "489 & 18 "925 & 18 "894 & 19 "759 \\
\hline
\end{tabular}

Nota: A1 - permaneceu $1,4 \%$ do tempo acima de $200 \mathrm{bpm}$ e 30,5\% entre 100 e $110 \mathrm{bpm}$

A2 - permaneceu 5,1\% do tempo acima de $200 \mathrm{bpm}$ e $43,9 \%$ entre 80 e $90 \mathrm{bpm}$;

A3 - permaneceu $7 \%$ do tempo acima de $200 \mathrm{bpm}$ e $29,7 \%$ entre 90 e $100 \mathrm{bpm}$;

A4 - permaneceu $8,3 \%$ do tempo acima de $200 \mathrm{bpm}$ e $25 \%$ do tempo numa faixa entre 90 e $100 \mathrm{bpm}$;

A5 - permaneceu 6,2\% do tempo acima de $200 \mathrm{bpm}$ e 35,6\% entre 100 a $110 \mathrm{bpm}$;

A6 - permaneceu 4,3\% do tempo acima de $200 \mathrm{bpm}$ e $32 \%$ entre 90 a $100 \mathrm{bpm}$.

${ }^{1}$ Polar S610 e Equine Transmitter.

2 Polar Horse Trainer. 


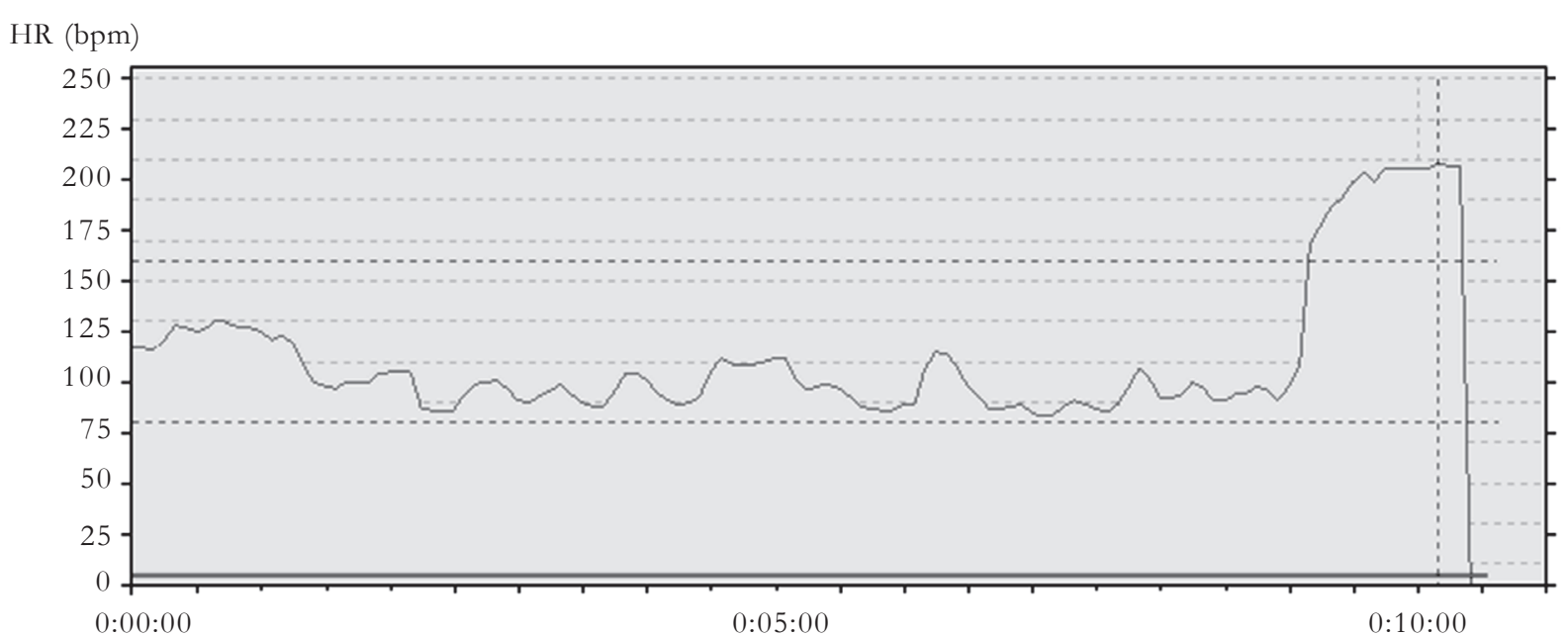

FIGURA 1 - Frequência cardíaca (FC) mensurada durante o período de aquecimento e de prova de tambor em cavalo da raça quarto-de-milha (A3). Observa-se uma faixa de FC constante durante o período de aquecimento e uma rápida resposta cardíaca no momento do esforço máximo durante a prova

Não foram verificadas diferenças significativas entre os valores encontrados nos animais avaliados. Analisando os gráficos de porcentagens entre tempo versus frequência cardíaca durante o período de aquecimento e de prova, foram encontrados os seguintes valores (Figura 2):

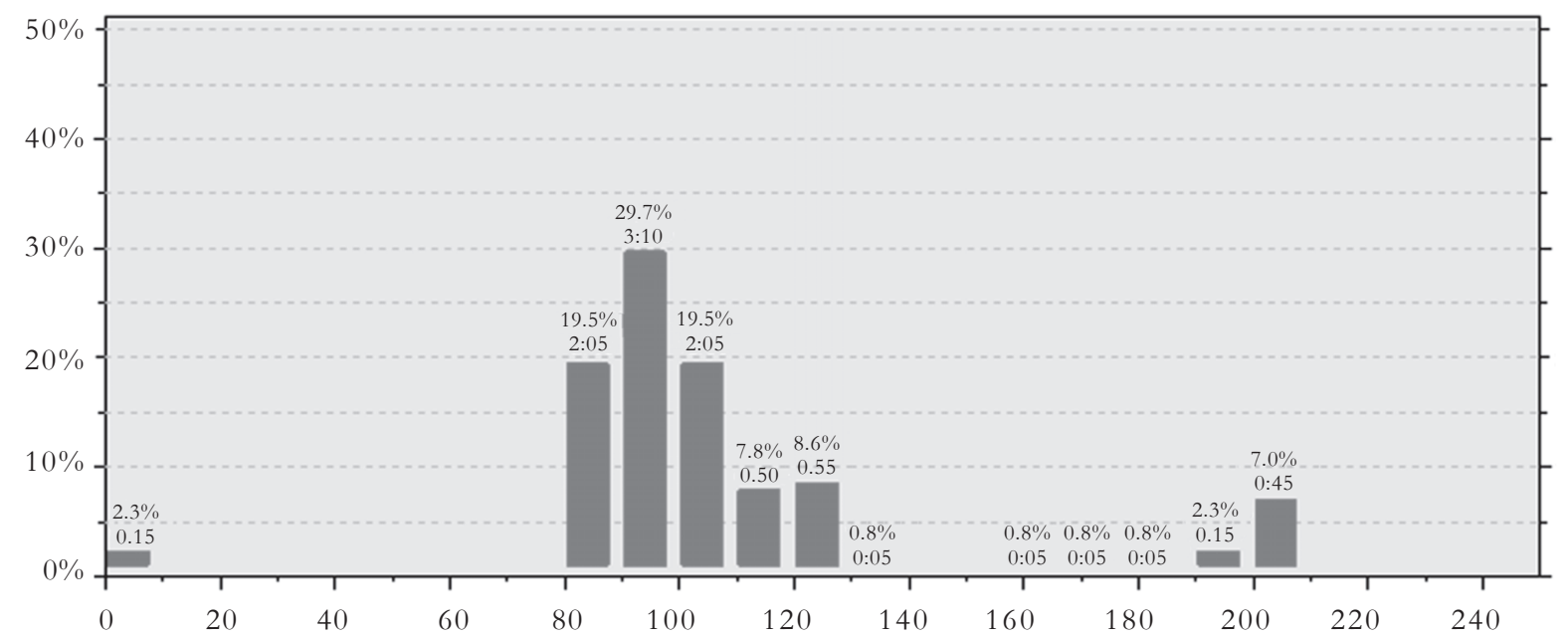

FIGURA 2 - Frequência cardíaca (FC) e o tempo de exercício do animal A3. Observa-se que em 29,7\% do tempo, a FC permaneceu na faixa de 90 a $100 \mathrm{bpm}$ e que 7\% do tempo a FC permaneceu acima de $200 \mathrm{bpm}$ 


\section{DISCUSSÃO}

Nenhum dado isolado tem a precisão de predizer a capacidade de exercício, já que a habilidade atlética é multifatorial (COUROUCÉ, 1999; EVANS, 2007). Por esta razão, sempre há necessidade da utilização de dados combinados, como realizado na presente pesquisa.

O hemograma é um dado bastante utilizado na rotina para o controle do desempenho de atletas (CONCEIÇẪO et al., 2001; REVINGTON, 1983; ROSE, 1990). Entretanto, a simples determinação do hematócrito após o exercício não é considerada confiável como indicador do volume total de células vermelhas, porque há variações no volume plasmático (HODGSON; ROSE, 1994). Como verificado com o resultado do hematócrito dos animais estudados na presente pesquisa, demonstrando a não ocorrência de variação entre eles.

Já as alterações no leucograma dependem da intensidade e duração do exercício, bem como do grau de estresse ao qual o atleta é submetido. A contagem total de leucócitos aumenta de 10 a 30\% após o exercício e está relacionada aos níveis de cortisol (SNOW et al., 1983).

Os valores determinados de hematócritos foram os mesmos encontrados por Conceição et al. (2001), após exercício de baixa intensidade em cavalos puro-sangue-inglês, porém, os valores de leucócitos totais foram maiores dos que por eles encontrados, corroborando que sua variação depende da intensidade do exercício (SNOW et al., 1983).

O fibrinogênio é um indicador sensível de processos inflamatórios e é útil como ferramenta para rastrear animais com queda de desempenho (EVANS, 2007; HODGSON; ROSE, 1994). Nos animais estudados, o valor encontrado estava dentro dos padrões de normalidade para todos os indivíduos, mostrando a confiabilidade da avaliação pré-pesquisa, para inserção dos animais no projeto.

A maneira mais simples para avaliar o desempenho em provas de velocidade é a determinação do tempo que o animal leva para percorrer determinada distância (HARKINS et al., 1993; MARLIN; NANKERVIS, 2002), sendo que a velocidade é a variável-chave na avaliação a campo (ANGELI; LUNA, 2008). Desta maneira, o tempo obtido nas provas pode ser utilizado como modo comparativo quando associado aos demais valores discutidos. Ainda segundo Corrêa e Mota (2007), a velocidade dos cavalos da raça quarto-de-milha deveria ser utilizada como parâmetro na seleção genética destes animais, dada sua importância como dado final na avaliação de desempenho atlética.

Como afirmado por Evans (2007), a velocidade em que o cavalo atinge a FC máxima é o melhor indicador da capacidade cardiovascular. Ainda, Harkins et al. (1993) sugerem que a FC de cavalos mais velozes aumenta mais rapidamente do que em cavalos com menor capacidade de atingir altas velocidades. $\mathrm{Na}$ análise descritiva dos dados, houve relação evidente entre a FC e a velocidade. Desta forma, pôde-se observar que a maior FC foi relacionada ao menor tempo de prova, como descrito Harkins et al. (1993). Esta observação é importante, uma vez que o quarto-de-milha é considerado o equino que atinge as maiores velocidades numa distância de 402 m, como relatado por Nielsen et al. (2006).

A simples avaliação a campo utilizada nesta pesquisa mostra que se pode acompanhar o desempenho de cavalos atletas com baixo custo, sem a necessidade de uma esteira de alto desempenho, como também descrito por Nostell et al. (2006). A mensuração da FC e a determinação do hemograma póscompetição foram informações satisfatórias para se determinar o nível de desempenho em que se encontrava determinado atleta. Estas são ferramentas baratas e extremamente úteis quando utilizadas a campo.

\section{CONCLUSÃO}

Os resultados indicam influência positiva dos altos valores da contagem total de eritrócitos e da frequência cardíaca sobre o menor tempo de prova obtido por cavalos da raça quarto-de-milha. 


\section{REFERÊNCIAS}

ANGELI, A. L.; LUNA, S. P. L. Aquapuncture improves metabolic performance in thoroughbred horses. Journal of Equine Veterinary Science, Illinois, v. 28, n. 9, p. 525-531, 2008.

CONCEIÇÃO, M. et al. Hemograma e bioquímica sérica de eqüinos da raça quarto de milha antes e após o exercício. Veterinária Notícias, Uberlândia, v. 7, p. 87-92, 2001.

CORREAA, M. J. M.; MOTA, M. D. S. Genetic evaluation of performance traits in Brazilian Quarter Horse. Journal of Applied Genetics, Poznan, v. 48, n. 2, p. 145-151, 2007.

COUROUCÉ, A. Field exercise testing for assessing fitness in French Standardbred Trotters. The Veterinary Journal, v. 157, p. 112-122, 1999.

EVANS, D. L. Physiology of equine performance and associated tests of function. Equine Veterinary Journal, London, v. 39, p. 373-383, 2007.

HARKINS, J. D.; BEADLE, R. E.; KAMERLING, S. G. The correlation of running ability and physiological variables in thoroughbred racehorses. Equine Veterinary Journal, London, v. 25, p. 53-60, 1993.

HINCHCLIFF, K. W.; GEOR, R. J.; KANEPS, A. J. Equine exercise physiology: the science of exercise in the athletic horse. Philadelphia: Saunders, 2007.

HODGSON, D. R.; ROSE, R. J. The athletic horse: principles and practice of equine sports medicine. Philadelphia: Saunders, 1994.

MARLIN, D.; NANKERVIS, K. Equine exercise physiology. Oxford: Blackwell Science, 2002.

NIELSEN, B. D. et al. Racing speeds of quarter horses, thoroughbreds and Arabians. Equine Veterinary Journal, London, v. 36, p. 128-132, 2006. Suplemento.

NOSTELL, K. et al. The physiological responses to simulated race tests on a track and on a treadmill in standardbred trotters. Equine Veterinary Journal, London, v. 36, p. 123-127, 2006. Suplemento.

OLDRUITENBORGH-OOSTERBAAN, M. M. S.; CLAYTON, H. M. Advantages and disadvantages of track vs. treadmill tests. Equine Veterinary Journal, London, v. 30, p. 645-664, 1999. Suplemento.

REVINGTON, M. Haematology of the racing thoroughbred in Australia 2: haematological values compared to performance. Equine Veterinary Journal, London, v. 15, n. 2, p. 145-148, 1983.

ROSE, R. J. Exercise and performance testing in the racehorse: problems, limitations and potential. In: ANNUAL CONVENTION OF THE AMERICAN ASSOCIATION OF EQUINE PRACTITIONERS, 1990, Lexington. Proceedings... Lexington: [s.n.], 1990. p. 491-504.

SNOW, D. H.; RICKETTS, S. W.; MASON, D. K. Hematological response to racing and training exercise in thoroughbred horses, with particular reference to the leukocyte response. Equine Veterinary Journal, London, v. 15, p. 149-153, 1983.

Recebido: 03/11/2008

Received: 11/03/2008

Aprovado: 20/01/2009

Approved: 01/20/2009 